\title{
EGFR NM_005228.3:C.2155G>T
}

National Cancer Institute

\section{Source}

National Cancer Institute. EGFR NM 005228.3:C.2155G>T. NCI Thesaurus. Code C98523.

A nucleotide substitution at position 2155 of the coding sequence of the EGFR gene where guanine has been mutated to thymine. 